\title{
ИМПОРТОЗАМЕЩЕНИЕ И ЭКСПОРТНООРИЕНТИРОВАННОЕ РАЗВИТИЕ В СТРОИТЕЛЬНОМ СЕКТОРЕ
}

\author{
(c) 2021 Кравченко Александр Викторович \\ доктор экономических наук, доцент \\ Санкт-Петербургский государственный архитектурно-строительный университет, \\ Россия, Санкт-Петербург \\ E-mail:kravstv@mail.ru
}

Исследовано современное состояние и теоретико-методологические аспекты развития импортозамещения в строительном секторе России. Обоснованы перспективные направления политики импортозамещения и экспортноориентированного развития в строительном секторе в условиях глобализации экономики.

Ключевые слова: импортозамещение, строительный сектор, насыщенность внутреннего рынка, конкурентоспособность продукции.

Постановка проблемы. На современном этапе строительный сектор России нуждается в глубоких социально-экономических трансформациях, что позволит повысить экономическую устойчивость и уменьшить зависимость страны от импорта строительных материалов. Наиболее реальные перспективы в значительной степени связаны с развитием национального рынка, что может быть реализовано за счет усиления ориентации отечественных предприятий на удовлетворение внутреннего спроса и развития производства импортозамещающих товаров. В условиях глобализации экономики импортозамещение может стать платформой не только для обеспечения экономической безопасности страны, но и для создания конкурентоспособной продукции.

Анализ последних исследований и публикаций. Вопросы импортозамещения и экономических национальных интересов страны исследовало ряд отечественных и зарубежных ученых: Д. Аакер, М. Альберт, И. Ансофф, А. Дайнеко, А.Данилов-Данильян, И.Дунаев, Я.Жалило, П.Кадочникова, М.Мескон, Е.Назарчука, Т. Остапенко, А.Пухкал, Ф.Хедоури и др. Однако аспекты импортозамещения в строительной сфере в научной литературе освещены фрагментарно. Нераскрытыми остаются механизмы формирования и имплементации стратегии импортозамещения в условиях глобализации экономики и привлечения России к мировым интеграционным процессам. Именно поэтому целью исследования является определение современного состояния и теоретико-методологическое обоснование перспектив использования импортозамещения в строительной сфере.

Изложение основного материала. В течение последних лет происходит постепенная потеря отечественными производителями ряда сегментов внутреннего рынка товаров, что связано со значительными структурными деформациями в экономике и низкой конкурентоспособностью многих предприятий. Низкие темпы расширения внутреннего рынка составляют угрозу национальной безопасности России в экономической сфере, ограничивая перспективы экономического роста в долгосрочной перспективе и формируя значительные риски для конкурентоспособности экономики. Учитывая сложившиеся внешнеторговые тенденции и характер факторов влияния на экономические процессы отечественных производителей, можно прогнозировать, что взаимодействие с дргими странами будет усложняться.

Перспективы промышленного строительства зависят от развития отечественной строительной отрасли, в частности от развития потенциала строительной науки и обновления материально-технической базы строительства. Возникновение значительного дисбаланса между спросом и предложением может привести к потере отечественными производителями сегментов продажи товаров, как на внутреннем, так и внешнем рынке. Такие обстоятельства побуждают к выработке стратегического подхода к решению проблемы расширения внутреннего рынка за счет увеличения доли товаров отечественного производства, а это предполагает 
разработку и внедрение процесса импортозамещения, роль которого только усиливается в современных условиях.

Поэтому для сохранения существующих позиций и наращивания их экономической эффективности промышленным предприятиям необходимо обеспечить переориентацию на потенциальных партнеров, как на востоке, так и на западе, что будет способствовать минимизации отрицательного торгового сальдо. Налаживание импортозамещающего производства позволит решить эти и другие вопросы и будет способствовать развитию государства в стратегическом плане [9].

Широкомасштабное внедрение процесса импортозамещения было одной из основных целей экономического развития в теоретических моделях представителей неокейнсианский школы - Н.Бруно, Н. Картера, А. Страуга, Х.Венере, которыми в 60-70-х годах XX века была предложена модель экономического роста с двумя дефицитами» путем постепенного вытеснения импортных товаров отечественными и замены внешних источников финансирования национальной экономики внутренними. Зато уменьшение дефицита накоплений и торгового дефицита в этой модели предлагалось компенсировать внешними заимствованиями.

В экономической теории термин «импортозамещение» не приобрел однозначное теоретико-методологическое содержание, не имеет четкой институционально-правовой трактовки, но широко и довольно свободно используется в политической лексике и публицистике [1].

В исследованиях [4; 8; 11] термин «импортозамещение» в основном трактуют как сокращение объема импорта путем введения таможенных ограничений с целью высвобождения внутреннего рынка для товаров-заменителей отечественного производства. То есть четко выделяется товарный аспект проблемы импортозамещения. Отметим, что стратегия внутриориентированного импортозамещения направлена на расширение внутреннего рынка товаров и услуг; внешнеориентированного импортозамещения-на продвижение отечественной продукции на мировой рынок; комплексного импортозамещения-на рост объема и доли реализации отечественных товаров как на внутреннем, так и на внешнем рынке.

По мнению некоторых ученых, импорто- замещение является разновидностью государственной политики, направленной на уменьшение потребности национальной экономики страны в импорте некоторых видов товаров благодаря увеличению доли их реализации на внутреннем рынке, производимых на ее территории [2].

Содержательные характеристики импортозамещения можно представить следующим образом:

- процесс замены импортных товаров отечественными не ниже уровня качественных и ценовых характеристик;

- наращивание внутреннего производства (промышленного или развития реального сектора) отечественных товаров;

- структурные сдвиги в элементах национальной экономической системы;

- улучшение торгового баланса страны;

- увеличение объемов экспорта товаров и услуг.

Поэтапная реализация стратегии импортозамещения приводит к положительным сдвигам в стране.

Модернизация производства сегодня является едва ли наиболее актуальной темой в экономических и политических кругах. Финансовый кризис 2008 г. и 2014 г. был одной из причин роста этого интереса, ведь стало понятно, что высокая доля сырья в экспорте делает нашу страну сырьевым придатком для развитых европейских стран, высокая зависимость от мировой конъюнктуры цен на нефть и газ делает национального производителя уязвимым. Нужно также учесть тот факт, что происходит значительное увеличение вовлечения всех стран в мировую экономику в процессе глобализации. Поэтому необходимо сконцентрировать свои усилия на развитии инноваций в производственных процессах бюджетообразующих отраслей государства.

На уровне государства одной из определяющих задач является развитие экспорта государства. Импортозамещение может выступать в качестве переходного этапа к экспортной ориентации, поэтому оно, безусловно, должно быть подчинено долгосрочной цели. Основной целью должна быть максимальная интеграция в мировое разделение труда, ориентация на производство тех товаров, которые являются наиболее конкурентоспособными.

Наращивание объемов экспорта и рост ВВП 
влечет за собой прирост импорта, так как в структуре готовой продукции содержится высокая доля импортных составляющих. Именно поэтому работа по снижению импортной продукции является очень важной и актуальной.

Политику импортозамещения называют также «импортозамещающей индустриализацией», ввиду того, что замена импортируемых товаров на отечественные преимущественно предполагает развитие отраслей, где производятся аналоги импортных товаров. При этом некоторые исследователи предлагают различать импортозамещение (import substitution) как замену импорта товарами, которые уже производятся внутри кршни, и импортозамена (mport replacement) - замену импорта товарами, которые страна может производить для собственных нужд [5].

Политику импортозамещения брали на вооружение многие страны, но далеко не во всех случаях она давала ощутимые и долгосрочные результаты. Таким примером могут выступать страны Латинской Америки. Успешные примеры использования импортозамещения показали Япония и Франция. Обе эти страны энергично защищали свои внутренние рынки, используя рост промышленности как средство стимулирования производителей для повышения конкурентоспособности продукции и выхода на внешние рынки. Обоснование политики замещения импорта было предоставлено заместителем министра внешней торговли и промышленности Японии господином В.Одзими [11]. Министерством было решено создать в Японии отрасли промышленности, которые требуют интенсивного использования капитала и техники, отрасли, которые, с точки зрения сравнительных издержек, были бы наиболее неподходящими для Японии, как, например, сталеплавильная, нефтеперерабатывающая, нефтехимическая, автомобильная промышленность, производство оборудования всех типов и электроника, включая производство компьютеров. С краткосрочной, статической точки зрения, поддержка таких отраслей промышленности должна противоречить экономической рациональности. Но с перспективной точки зрения, это - именно те отрасли, где эластичность спроса по доходу высока, технологический прогресс интенсивен, а производительность труда быстро растет. Таким образом, стратегия импортозамещения в Японии, так же как и стратегия Франции в 50-х гг., заключалась в использовании роста промышленности в пределах национального рынка как трамплина для завоевания экспортных рынков, а экспорт стимулировалось внутренним ростом экономики.

Платформой для роста национальной экономики является развития в строительной сфере. Наращивание экономического потенциала должно происходить в контексте внешнеэкономической политики государства, что в результате приведет к производству товаров с высокой добавленной стоимостью.

Начальный этап должен базироваться на расширении национального спроса, в частности, с помощью протекционистских мер, а внутренние сбережения и налоговые поступления будут финансировать внутренние инвестиции. Развитие конкуренции и насыщение национального рынка является основой повышения конкурентоспособности продукции, что в дальнейшем, позволит наращивать удельный вес в международной торговле. Кроме того, развитие национальных производств вызывает ряд положительных экстерналий: увеличение вложений в технологическое обновление предприятий, развитие инфраструктуры, создание рабочих мест, рост спроса на высококвалифицированные кадры, переориентацию на производство продукта с высокой добавленной стоимостью.

В течение определенного периода процесс экономического роста будет носить самоподдерживающийся характер. Однако данный этап должен были лишь переходным звеном к развертыванию активной стратегии экспортоориентированного развития, ведь именно экспорт формирует основу платежеспособности. В частности, в Южной Корее и Тайване высокий уровень внешнеторговой протекции сохранялся до начала 80-х годов. После создания на базе политики импортозамещения устойчивых развитых предприятий с эффективной экономической стратегией - «национальных чемпионов», способных конкурировать на мировых рынках, был осуществлен постепенный переход к экспортной ориентации и ослабление ограничений на импорт. Кроме того, в условиях глобализации главной целью стратегии импортозамещения должно быть стимулирование производства конкурентоспособных товаров на мировом рынке. Именно поэтому импортозамещение в производственных сферах требует инновационного развития экономики. 
Значительный потенциал импортозамещения существует в строительной сфере. Устойчивое наращивание импорта продукции, в частности стройматериалов, создает угрозу экономической безопасности страны [6; 10]. Несмотря на то, что торговый баланс строительного сектора является позитивным, при отрицательном сальдо в целом по экономике структура внешней торговли является несбалансированной.

В России наблюдается тенденция роста удельного веса экспорта сырья, а в импорте готовой продукции. В структуре импорта увеличивается доля стройматериалов, которую Россия традиционно экспортировала, что свидетельствует о потере возможности реализовывать экономические интересы страны.

Отметим, что строительная отрасль России обладает значительным производственным потенциалом. Основным отечественным товаром на внешних рынках являются: природные (естественные) каменные материалы, неорганические и органические материалы, бетон, железобетон, лесные материалы, металлы [7]. Такая сырьевая направленность делает внешнеторговые позиции государства уязвимыми на мировом рынке, ведь спрос на сырьевые товары характеризуется высокой изменчивостью, а доля добавленной стоимости такой продукции очень низкая, что снижает эффективность экспортного потенциала страны. В целом главной особенностью является то, что при всех колебаниях объемов наблюдается тенденция к наращиванию темпов роста положительного сальдо. В то же время неприемлемая тенденция роста доли экспорта строительного сырья по сравнению с экспортом полуготовой и готовой продукции перерабатывающей промышленности обуславливает потерю добавленной стоимости, которую в дальнейшем создают страны-импортеры.

Причинами увеличения доли стройматериалов на отечественный рынок являются: во-первых, оптимальное сопоставление цены и качества присуще зарубежным странам; во-вторых, более широкий ассортимент в сравнении с российской продукцией; в-третьих, неспособность отечественных производителей удовлетворять спрос, который складывается на рынке в течение целого года.

Осуществление программы, возможно в рамках: во-первых, восстановления предыдущих производств, которые были утрачены в результате прекращения финансирования или других обстоятельств; во-вторых, технической, технологической модернизации существующих предприятий, использование биотехнологических средств и достижений научно-технического прогресса с целью повышения конкурентоспособности продукции; в-третьих, экстенсивного развития отрасли путем увеличения площадей и объемов производства.

Зависимость от импорта связана с несоответствием структуры производства потребностям внутреннего рынка и низкой конкурентоспособностью значительного количества отечественных товаров. На сегодняшний день экспорт большого количества сырья сформировался вследствие низкого совокупного спроса и уровня цен на национальном рынке. Такая тенденция не может гарантировать долгосрочные экспортные перспективы, ведь конкурентоспособные позиции отрасли на внешних рынках должны формироваться в условиях ценовой конкуренции и насыщенности внутреннего рынка. Учитывая это, целесообразным является внедрение политики импортозамещения в отношении тех групп товаров, где импорт преобладает над экспортом.

Считаем целесообразным определить последовательность государственной политики импортозамещения в строительной сфере. При ее соблюдении акцент будет делаться на укреплении конкурентоспособности отечественного производства, а отдельные протекционистские меры будут использоваться скорее для поддержки и более быстрого достижения целей реформ.

Предлагаемая нами концептуальная последовательность государственной политики состоит из трех принципиальных этапов.

Это, во-первых, анализ и выявление на его основе возможностей и потенциала импортозамещения.

Второй принципиальный этап реализации государственной политики импортозамещения касается восстановления позиций и улучшения конкурентоспособности отечественного производства.

Третий этап, по нашему мнению, должно касаться закрепления, а в дальнейшем и усиление позиций на внутреннем рынке продукции отечественного производства уже в большей степени силами системы товародвижения и инфраструктуры торговли.

Как следствие, есть две позиции по импор- 
тозамещению, которые делают акценты на положительных и отрицательных последствиях этого явления. К положительным социальноэкономическим последствиям государственной политики импортозамещения целесообразно отнести:

- становление и развитие важных для национального хозяйства видов экономической деятельности;

- обеспечение защиты более слабых по конкурентоспособности отечественных предприятий;

- создание условий для перехода к экспортно-ориентированной экономике благодаря введению таможенных ограничений и стимулированию экспорта импортозамещающей продукции;

- поддержку производителей импортозамещающей продукции, которые обеспечивают больший социальный эффект;

- создание инфраструктуры финансовоинвестиционных институтов для стимулирования инноваций, внедрения новых технологий и регулирования прямых иностранных инвестиций;

- формирование кластеров производственных предприятий, которые завоевывают устойчивые конкурентные позиции на внешнем рынке и превращаются из дотационных в бюджетонаполняющие со значительным внутриэкономическим социальным эффектом.

Однако отдельные ученые негативно оценивают роль импортозамещения, считая, что универсальным регулятором в открытых экономиках является рынок. Главными негативными последствиями здесь отмечаются:

- низкая эффективность импортозамещающего производства;

- переток большей части дохода и прибыли иностранных компаний, которые разворачивают внутри страны производство собственной продукции;

- углубление импортозависимости и отток иностранной валюты вследствие использования инвестиционно-технологического обеспечения и промежуточных товаров импортного происхождения;

- замедление развития в тех сегментах реального сектора экономики, где внедряется импортозамещение, поскольку предприятиям не удается нарастить достаточный потенциал конкурентоспособности из-за чрезмерного исполь- зования таможенных ограничений.

В то же время, государственная политика импортозамещения в строительной отрасли должна быть направлена на инновационную перестройку самой строительной отрасли.

Кроме того, в контексте общемировой тенденции и современного вектора движения рыночной экономики по траектории «от рыночной экономики до социальной рыночной экономики», «от социальной рыночной экономики - к экосоциальной рыночной экономики» результатом инновационных усовершенствований в строительной отрасли должно стать не только обеспечение современными средствами предприятий, но и улучшение качества окружающей среды и социально-экономического развития государства.

Вместе с тем, опыт стран с развитой рыночной экономикой свидетельствует, что даже в периоды экономического оживления и циклического подъема на рынке подрядных работ без дополнительных стимулов со стороны государства самостоятельно не возникает значительный спрос на проекты по реконструкции, модернизации и технического переоснащения производственных мощностей или инфраструктурных объектов на инновационной и экологической основе, поскольку с учетом ожидаемой доходности (прибыльности) реализации инвестиционных проектов предпочтение отдается проектам с минимальной инновационной составляющей мощностей. Эти противоречия обязательно нужно учитывать при разработке и имплементации государственной инвестиционной политики в строительной отрасли, а также при определении оптимальных границ дерегуляции инвестиционных процессов в этой сфере.

В последние три года в нашей стране произошла некоторая смена инвестиционных приоритетов в строительной отрасли.

Перспективы промышленного строительства зависят от развития отечественной строительной отрасли, в частности от развития потенциала строительной науки и строительного проектирования, обновления материальнотехнической базы строительства. Российские строительные организации не имеют мобильной базы, которая позволяла бы им выполнять масштабные заказы за пределами страны и маневрировать во время кризиса.

Проектно-технологическая и строительномонтажная деятельность в промышленной 
сфере должна ориентироваться на мобильные модульные технологии, облегченные металлические конструкции, методы последовательнопараллельного строительства, обеспечивающие сокращение сроков строительства, удешевление фундаментных работ, функциональность объектов и возможности сооружения их в сложных условиях.

В то же время, вследствие затягивания застройщиками строительства объектов недвижимости во времени права инвестора как стороны по договору подряда являются нарушенными, и такими нарушениями ему наносятся финансовые убытки.

Как правило, размер убытков инвестора при затягивании сроков строительства равен стоимости аренды помещения, аналогичного проинвестированному по своим параметрам (площадь, технические характеристики, расположение и т. п).

Вторая, но не менее важная проблема - это проблема высоких рисков не завершения строительства объекта недвижимости. Возникновение этой проблемы, как правило, связано с ошибками застройщика, его партнеров и контрагентов в экономических расчетах реализации проекта или влияние непредсказуемых внешних для проекта факторов (рейдерские захваты, корпоративные конфликты, политические и экономические факторы). Проблема проектов с высоким риском незавершения строительства является сложной, характеризуется высоким уровнем напряженности в отношениях между инвестором и застройщиком, однако при условии правильных действий застройщика эту проблему возможно решить.

Основными причинами, сдерживающими импортозамещение в строительном производстве и строительной отрасли, являются нестабильность политической ситуации, теневые и разного рода спекулятивные процессы в инвестиционно-строительной сфере, высокие налоги и риски инвестиционной деятельности, большая стоимость заемного капитала и сложность получения кредита, а также другие факторы, характеризующие инвестиционный климат России как неблагоприятный. В контексте выше- упомянутых причин инвестиционная политика в строительной отрасли должна органическим образом сочетать инструменты государственного влияния и дерегуляции с целью создания благоприятной инвестиционной среды как для отечественных, так и иностранных инвестиций.

Важнейшее значение для выхода инвестиционной сферы из кризисного состояния имеет увеличение количества небольших частных строительных фирм и фирм по производству отдельных видов строительных материалов, изделий и конструкций. В то же время, в условиях дефицита собственных капиталовложений, необходимых для проведения структурной перестройки экономики, решения проблем ее интеграции в мировую экономику, важное значение приобретает привлечение внешних источников финансирования, в том числе иностранных инвестиций.

\section{Вывод.}

Обобщение опыта разных стран относительно практики применения импортозамещения для обновления внутренней экономики позволило определить проблемы и перспективы реализации импортозамещения отечественными производителями строительной отрасли. Определение рациональных мотивов формирования и реализации стратегии импортозамещения позволяет сформировать более четко миссию и задачи опережающего развития в неустойчивых внешних условиях.

В строительном секторе экономики существует значительный потенциал импортозамещения. Формирование конкурентоспособных позиций отрасли и стимулирования повышения иностранного спроса должно происходить в условиях конкуренции и насыщенности внутренних рынков, что способна обеспечить политика импортозамещения по отношению к тем группам товаров, где импорт преобладает над экспортом. Для развития импортозамещения важным является углубление механизма стимулирования производства в строительном секторе - заменителей импорта, что будет включать инструменты денежно-кредитной, фискальной, валютно-курсовой и внешнеторговой политики.

\section{Библиографический список}

1. Богданова Н.А. Динамика развития торговли и импортозамещение в России в условиях экономического кризиса / Н. А. Богданова, А. С. Никоненко // В сборнике: Экономика и предпринимательство в глобальном мире. Ростов-на-Дону, 2017. С. 25-35. 
2. Золотухина А. О. Федеральные и региональные аспекты экономической трансформации: экспортоориентированное импортозамещение / А. О. Золотухина // В сборнике: Экономика и предпринимательство в глобальном мире. Ростов-на-Дону, 2017. С. 95-103.

3. Институт исследований торговли и коммерческой дипломатии. [Электронный ресурc]. URL: http: // www. itcdonline.com/introduction/glossary2_i-p.

4. Кузнецова А.С. Импортозамещение как фактор роста экономики страны / А.С. Кузнецова, А. Ю.Козлова, Ю. В. Сорокина // Сборник статей международной научно-практической конференции. 2016. С. 125-129.

5. Присяжная М.А. Направление конкурентных преимуществ овощеводства в условиях импортозамещения / М.А.Присяжная // В сборнике: Наука и молодежь: новые идеи и решения. Материалы ХІ Международной научно-практической конференции молодых исследователей. 2017. С. 56-57.

6. Прядко И.П.Импортозамещение в сфере строительства и производства строительных материалов: постановка проблемы / И. П. Прядко // Научное обозрение. 2016. № 9. С. 119-122.

7. Соболева Е. А. Импортозамещение в строительной сфере: перспективы девелопмента / Е. А. Соболева // Экономика и предпринимательство. 2016. № 2-1 (67). С. 622-627.

8. Черкесова Э. Ю. Формирование организационно-экономического механизма реализации политики импортозамещения в Российской Федерации / Э. Ю. Черкесова, Д. Д. Миронова // Сборник научных статей. 2017. С. $138-145$.

9. Shonfield, A. Modem Capitalism. Oxford: Oxford University Press., in. 1962.

10. Levine R. Sensitivity Analysis of Cross - Country Growth Regression / Levine R. Renelt D. - American Economic Review 82.- 1992.- P. 942-963.

11. Ojimi, V. 1970. Japan's industrialization strategy. In OECD, Japanese Industrial Policy, Paris: OECD. 